\title{
Energy: The Link between GDP and Emissions
}

\author{
Jan-Erik Lane \\ University of Freiburg, Germany \\ E-mail: janeklane@googlemail.com
}

Received: December 17, 2012

Accepted: January 18, $2013 \quad$ Online Published: March 7, 2013

doi:10.5430/rwe.v4n1p49

URL: http://dx.doi.org/10.5430/rwe.v4n1p49

\begin{abstract}
The global energy-environment conundrum unfolds now with more and more evidence confirming the climate change hypothesis. The accumulation of greenhouses gases in the atmosphere is strongly linked with economic production, the GDP indicator. Here we give the exact relationships between GDP, energy consumption and greenhouse gases emissions, over time and cross-sectionally for the entire globe. The intermediating link between total GDP and total emissions is, it must be emphasized, the energy consumption, which has increased dramatically since 1970. It is true that the energy consumption per GDP unit has fallen, but the increase in GDP is more than enough to guarantee that energy consumption per capita continues to rise.

Keywords: Climate change, Global warming, Greenhouse gases, The GNP-energy-emissions link, Energyenvironment conundrum, Global energy consumption, Total and relative energy consumption

\section{Introduction}

When evaluating the overall environmental condition of Planet Earth, discussing the ecological deficits, the emission of greenhouse gases as well as the prospect of sustainability, one should include an analysis of the energy consumption of the countries of the globe. Below it will be shown that total GDP, total energy consumption and total emissions of greenhouse gases go closely together, making for a most difficult energy-environment conundrum. Due to the huge numbers involved in measuring these three components in the global energy-environment conundrum, the data will be stated in logarithms.
\end{abstract}

\section{Omnipresence of Energy}

Energy is defined as the capacity to do work, which is why it is so incredibly relevant to all activities, resulting in outcomes and change, also within all forms of social systems. Without energy, economic systems would not accomplish anything. There are several forms of energy, but what is essential to human beings is the energy that they can somehow retrieve and employ. Thus, economic production today needs massive amounts of energy all the time.

Physics teaches us that energy is indestructible. Given the existence of billions of galaxies, the total amount of energy in the Universe is truly astronomical. But, again it must be underlined that what counts for mankind at the 21 rst century is the access to usable energy. And energy must not become too costly, undermining the laudable Millennium Goals of the United Nations, reducing poverty and unhealthiness.

Let us below look at the major features of the global system of energy consumption and relate it to economic output (GDP) as well as to global emissions of greenhouse gases. Not only energy and economic output is linked, but also energy consumption and the environmental predicament of the globe. When the global market economy consumes enormous amounts of energy to deliver goods and services to 7 billion humans, it is urgent that the energy consumed is not transformed into a state that is harmful to life on planet Earth, promoting a kind of gigantic condition of entropy.

2.1 Time: 1970 - 2008

Employing most recently available information from the US Energy Administration information, one may draw a picture of the immense need of Planet Earth for energy. Energy consumption has more than doubled since 1970, following almost exactly the immense growth in global GDP.

The EAI predicts another doubling of global energy consumption for the coming 20-30 years, reflecting similar projections for global economic growth. One may question such future extrapolations, citing the increasing difficulties in providing the globe with relatively inexpensive energy from mainly fossil fuels. The prospects of 
replacing non-renewable energy sources with renewable ones seem not to as promising as the environmental movement beliefs. When the global market economy faces its Hubbert Peak for conventional petrol production from ordinary oil wells, then it seems likely that one will resort to the production of massive amounts of shale oil and gas, which will probably increase the emission of greenhouse gases.

Figure 1 maps the link between total GDP and total energy consumption since 1970.

$<$ Insert Figure 1 Here $>$

When there is economic activity, energy is consumed: transportation on land, sea and in air, shipping, minerals extraction, tourism, manifacture, agriculture, supply of services, provision of heating and light, communications, etc. And energy consumption, especially the burning of fossil fuels results in the emission of greenhouse gases (Figure 2).

Turning to Figure 2, one observes a similar very close link, this time between energy consumption and global emissions. Energy consumption constitutes the link between the observed connection between GDP and emissions of $\mathrm{CO} 2$ equivalent gases. Both small scale and large scale economic activities consume energy, which leads to emissions. Thus, once the EAI predicts a strong increase in energy consumption for the decades ahead, it also must admit that emissions will continue go up. Climate change is unavoidable. Global economic activity is far from sustainability when it comes to the emission of greenhouse gases.

$<$ Insert Figure 2 Here $>$

One may look at the country variation for most recently available year in order to find out whether the same logic applies to the cross-sectional variation in GDP, energy consumption and emissions of greenhouse gases,

\subsection{Space: 2008}

One observes in Figure 3 that total energy consumption is linked with total country GDP, as for 2008. One may surely expect the same link to apply for country energy consumption and country emissions, as long as one focuses upon totals. Thus, it holds both longitudinally and cross-sectionally that the higher the total GDO, the larger the energy consumption.

$<$ Insert Figure 3 Here>

The hypothesis that higher elevels of energy consumption results in higher levels of emissions on a linear basis is corroborated in Figure 4, containing the cross-sectional evidence.

$<$ Insert Figure 4 Here $>$

Figure 5 relates energy consumption per GDP unit to country GDP in a search for an efficiency effect: the larger the GDP, the less the energy used per GDP unit. There is no clear trend, but for some countries hold that energy per GDP falls somewhat the bigger country GDP is.

$<$ Insert Figure 5 Here $>$

This is an important finding, but it does not allow for any hope of considerable future efficiency gains, neither in energy consumption nor in emission reductions. One finds the same lack of a trend when one looks at energy consumption per capita against the size of the country- Figure 6. In general, one would expect that energy per capita would tend to be higher the richer the country in terms of GDP per capita, but several poor and medium income countries display inefficiences in energy usage per capta when compared cross-sectionally.

$<$ Insert Figure 6 Here $>$

\section{Macro Energy Efficiency}

A much debated question in reflections upon the global energy-environment conundrum is whether one may detect over time signs of increasing energy efficiency, speaking of totals. One would be inclined to argue that more of macro energy efficiency would ameliorate the energy-environment conundrum, but it is in fact more complicated a matter, as other factors play a role.

$<$ Insert Figure 7 Here $>$

Although one finds this seminal trend towards macro efficiency in energy consumption for global GDP over time, one has to bear in mind that GDP has increased so much that the energy consumption per capita in the world has risen sharply. Energy consumption per capita has risen sharply with the expansion in world population- see Figure 8.

$<$ Insert Figure 8 Here $>$ 
Higher level of affluence (GDP) and a bigger population are conducive to a higher level of total energy consumption, which leads to bigger total emissions. Countries do not wish to reduce the rates of economic development in order to bring energy consumption down, which would also decrease total emissions. Although the energy consumption per GDP unit tends to decline, the energy consumption keeps going up with rapid economic development, undoing the efficiency gains.

\section{The Energy-Environment Conundrum}

Energy consumption has doubled since 1970, driven by the immense economic development with constant positive growth rate for the global market economy. Although economic advances make it possible to reduce poverty, they require more and more of energy, the consumption of which leads to the emission of greenhouse gases, especially when energy is derived from the burning of fossil fuels. As energy consumption is predicted to expand in the near future in the same fashion, there is cause for worrying about the global environment: greenhouse gases and climate change. Mankind must find ways of retrieving great amounts to energy in ways that are much less polluting, meaning turn to renewable energy sources with neutral carbon impact. The feasibility of massive use of renewables that are carbon neutral depends at the end of the day upon the price of conventional energy as well as the impact of the arrival of shale oil and gas.

\section{Conclusion}

The key component in the energy-environment conundrum that is set to become the perhaps number ONE problematic for Planet Earth during the 21 rst centry is energy consumption. It has increased enormously the last decades and is expected by the EIA to keep growing rapidly in the decades to come. However, it is strongly linked with the emissions of greehouse gases. One may estimate these "iron law" type connections, both over time and across space by means of regression equations. The findings reported on here are crystal clear: Reducing energy consumption would mean halting economic growth, as GDP determines overall energy consumption, which in turn determines to a large extent the total emissions of $\mathrm{CO} 2$ equivalent types. Especially the emerging economies, eager to "catch-up", reject proposals for a global emissions regime that would make energy more expensive. Yet, not all countries are equally emissions efficient, given their energy consumption. As Figure 9 indicates, China for instance could do a lot better in its emissions-energy equation.

$<$ Insert Figure 9 Here $>$

Given the strong links between economic activity (GDP), energy (energy consumption) and emissions (CO2 equivalent emissions), it is hardly a surmise that climate change in inevitable.

Since the basic links between GDP, energy consumption and total emissions remain positive, there is no hope for the stabilisation of the level of greenhouse gases in the future. The recent advent of the massive use of shale oil and gas is cause for pessimism, as the decisive turn to renewable energy sources may be delayed some 10 years. Planet Earth is heading for global warming with all the uncertainties and risks involved.

\section{References}

Energy and emissions data: International Energy Agency (IEA Statistics (C) OECD/IEA. [Online] Available: http://www.iea.org/stats/index.asp

GDP data: World Bank indicators. [Online] Available: http://data.worldbank.org/indicator

Population data:

Census reports and other statistical publications from national statistical offices,

Eurostat: Demographic Statistics,

Secretariat of the Pacific Community: Statistics and Demography Program, and

U.S. Census Bureau: International Database.

United Nations Population Division. World Population Prospects,

United Nations Statistical Division. Population and Vital Statistics Report (various years) 


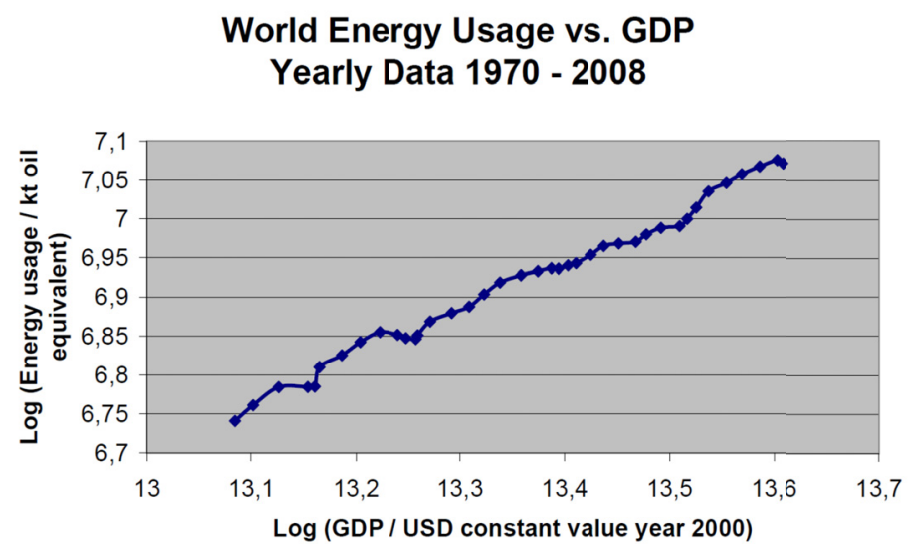

Figure 1

Note: Regression $=\mathrm{R} 2=0.988(\log \mathrm{y}=1.64 * \log \mathrm{x})$.

\section{World CO2 emissions vs. Energy usage \\ Yearly data 1970 - 2008}

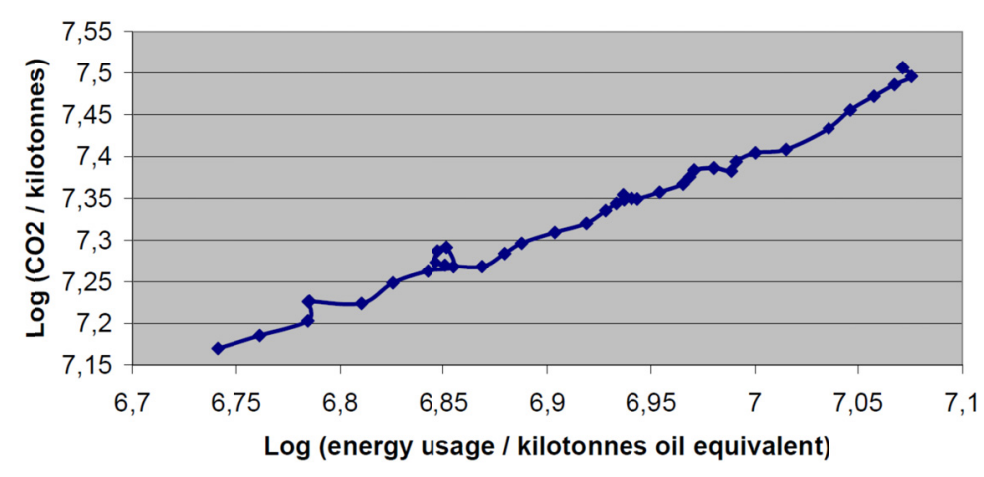

Figure 2

Note: Regression $=\quad R 2=0.982(\log y=2.5 * \log x)$.

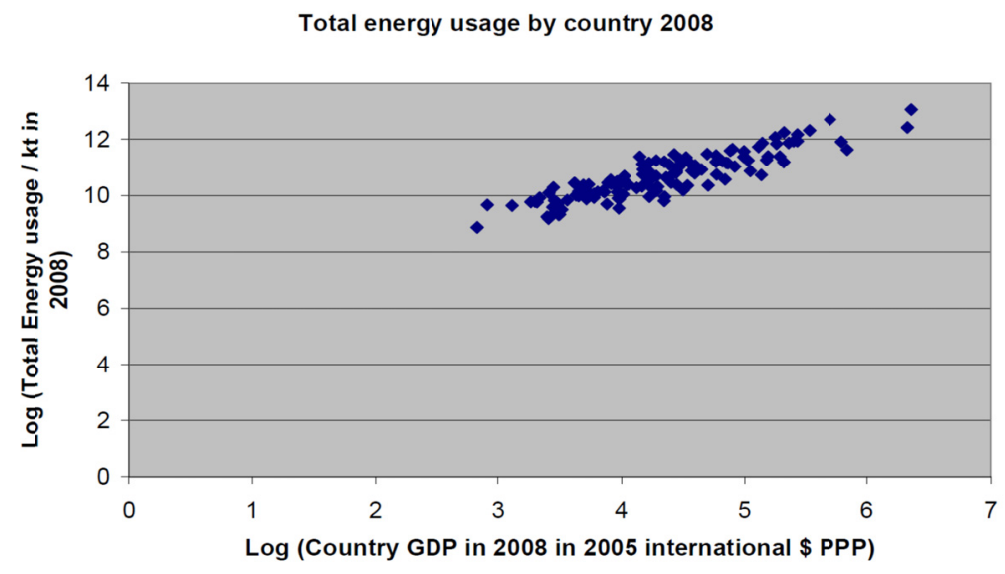

Figure 3

Note: Regression $=\mathrm{R} 2=0.697(\log \mathrm{y}=1.04 * \log \mathrm{x})$ 
Total emissions by country 2008

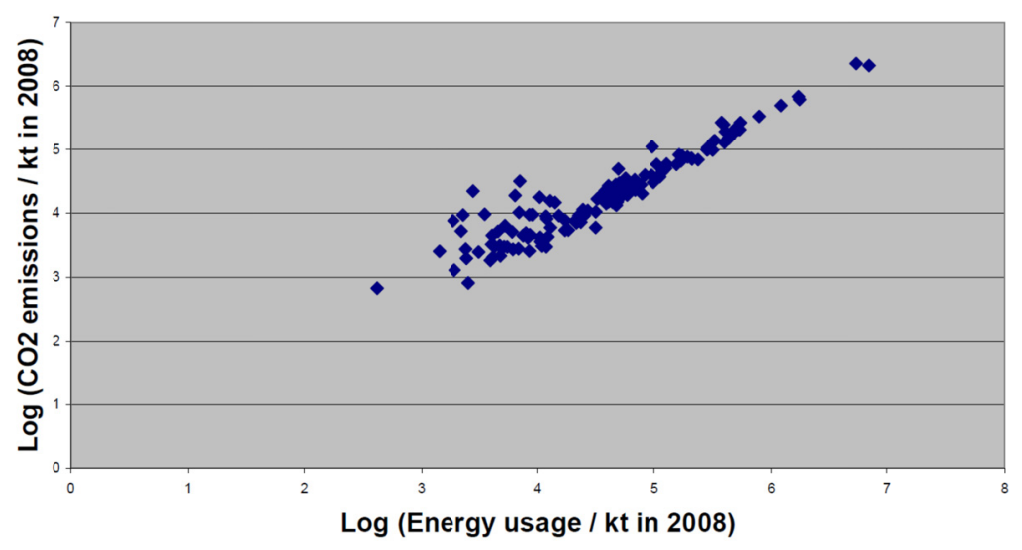

Figure 4

Note: Regression $=\mathrm{R} 2=0.970(\log \mathrm{y}=2.79 * \log \mathrm{x})$.

Energy usage per GDP by country 2008

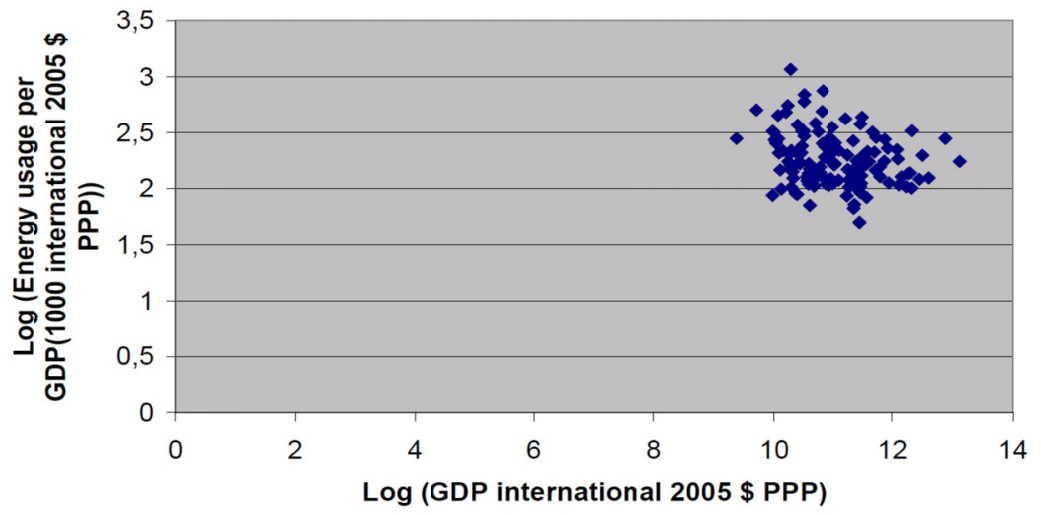

Figure 5

Note: Regression $=\mathrm{R} 2=0.0048$.

Energy per capita by population 2008

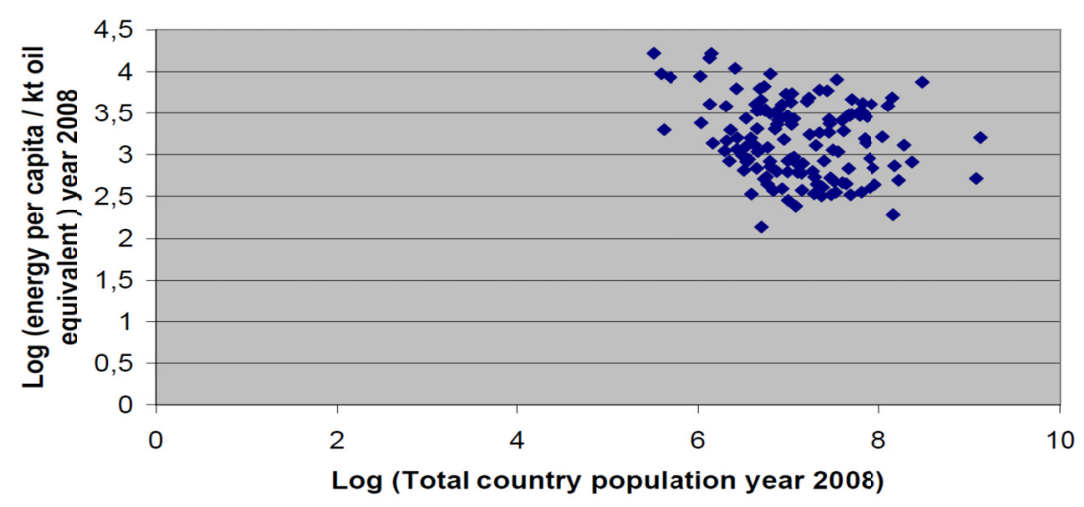

Figure 6

Note: Regression $=\mathrm{R} 2=0.0034$. 


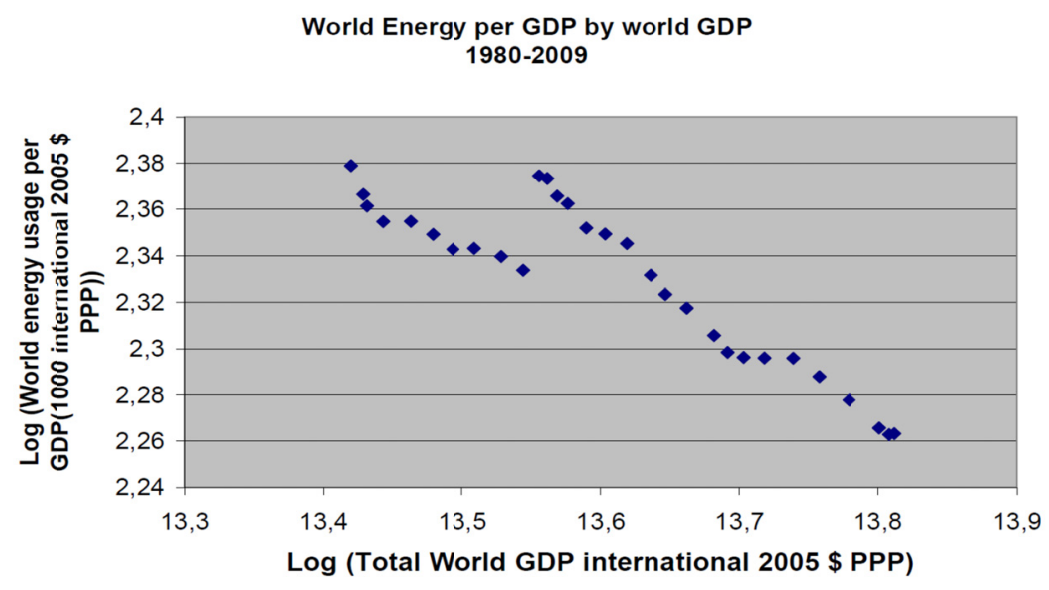

Figure 7

Note: Regression $=\mathrm{R} 2=0.852(\log \mathrm{y}=-0.26 * \log \mathrm{x})$.

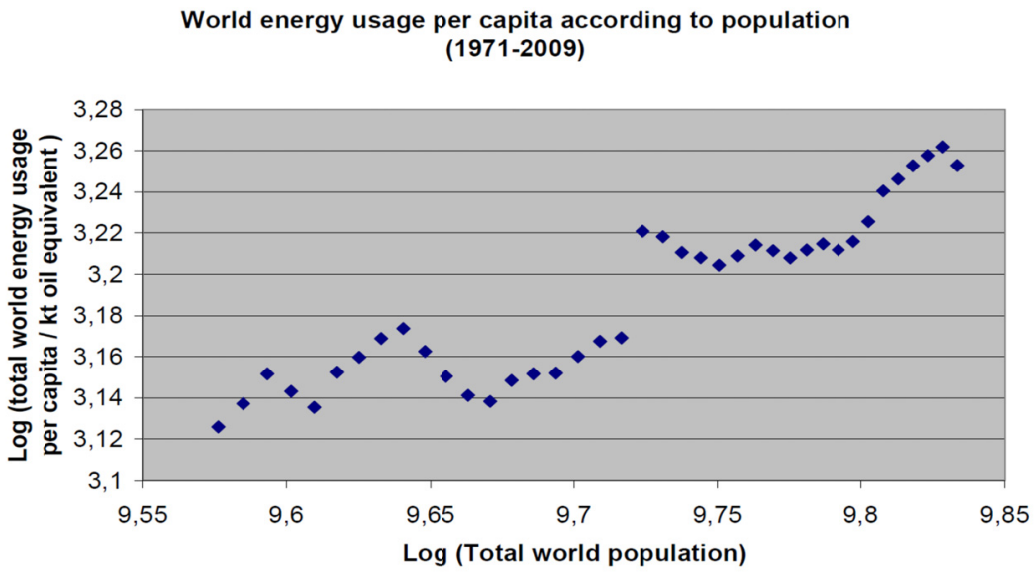

Figure 8

Note: Regression $=\mathrm{R} 2=0.8477(\log : \mathrm{y}=-1.4331+0.4757 \mathrm{x})$

Energy usage and $\mathrm{CO} 2$ emissions 2008 (World Bank Indicators)

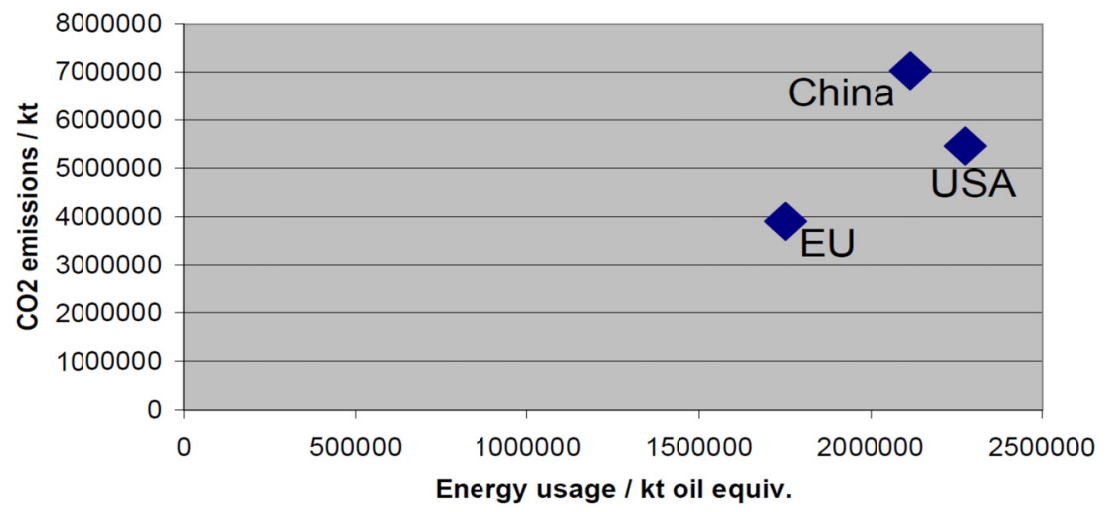

Figure 9 